\title{
HIF- $1 \alpha$ response to hypoxia is functionally separated from the glucocorticoid stress response in the in vitro regenerating human skeletal muscle
}

\author{
Sergej Pirkmajer, ${ }^{1}$ Dragana Filipovic, ${ }^{2}$ Tomaz Mars, ${ }^{1}$ Katarina Mis, ${ }^{1}$ and Zoran Grubic ${ }^{1}$ \\ ${ }^{1}$ Laboratory for Molecular Neurobiology, Institute of Pathophysiology, Faculty of Medicine, University of Ljubljana, \\ Ljubljana, Slovenia; and ${ }^{2}$ Vinca Institute of Nuclear Sciences, Laboratory of Molecular Biology and Endocrinology, \\ Belgrade, Serbia
}

Submitted 23 February 2010; accepted in final form 12 October 2010

Pirkmajer S, Filipovic D, Mars T, Mis K, Grubic Z. HIF-1 $\alpha$ response to hypoxia is functionally separated from the glucocorticoid stress response in the in vitro regenerating human skeletal muscle. Am J Physiol Regul Integr Comp Physiol 299: R1693-R1700, 2010. First published October 13, 2010; doi:10.1152/ajpregu.00133.2010.-Injury of skeletal muscle is followed by muscle regeneration in which new muscle tissue is formed from the proliferating mononuclear myoblasts, and by systemic response to stress that exposes proliferating myoblasts to increased glucocorticoid (GC) concentration. Because of its various causes, hypoxia is a frequent condition affecting skeletal muscle, and therefore both processes, which importantly determine the outcome of the injury, often proceed under hypoxic conditions. It is therefore important to identify and characterize in proliferating human myoblasts: 1) response to hypoxia which is generally organized by hypoxia-inducible factor- $1 \alpha$ (HIF- $1 \alpha)$; 2) response to GCs which is mediated through the isoforms of glucocorticoid receptors (GRs) and 11 $\beta$-hydroxysteroid dehydrogenases (11 $\beta$-HSDs), and 3) the response to GCs under the hypoxic conditions and the influence of this combination on the factors controlling myoblast proliferation. Using real-time PCR, Western blotting, and HIF-1 $\alpha$ small-interfering RNA silencing, we demonstrated that cultured human myoblasts possess both, the HIF- $1 \alpha$-based response to hypoxia, and the GC response system composed of GR $\alpha$ and types 1 and $211 \beta$-HSDs. However, using combined dexamethasone and hypoxia treatments, we demonstrated that these two systems operate practically without mutual interactions. A seemingly surprising separation of the two systems that both organize response to hypoxic stress can be explained on the evolutionary basis: the phylogenetically older HIF- $1 \alpha$ response is a protection at the cellular level, whereas the GC stress response protects the organism as a whole. This necessitates actions, like downregulation of IL-6 secretion and vascular endothelial growth factor, that might not be of direct benefit for the affected myoblasts.

hypoxia-inducible factor- $\alpha$; antisense version of hypoxia-inducible factor; vascular endothelial growth factor; glucocorticoid receptors; $11 \beta$-hydroxysteroid dehydrogenases

TWO PROCESSES ARE TAKING PLACE in mammalian organisms as a response to muscle injury. One is muscle regeneration in which new muscle tissue is formed from the proliferating mononuclear myoblasts originating from the mitotically and metabolically dormant satellite cells located under the basal lamina of the injured muscle fibers $(9,12)$. The second one is a systemic response to stress that leads to exposure of proliferating myoblasts to the increased glucocorticoid (GC) concentration (42).

Address for reprint requests and other correspondence: Z. Grubic, Laboratory for Molecular Neurobiology, Institute of Pathophysiology, Faculty of Medicine, Univ. of Ljubljana, Zaloska 4, 1000 Ljubljana, Slovenia (e-mail: zoran.grubic@mf.uni-lj.si).
Because of a great variety of its causes, hypoxia is among frequent conditions affecting skeletal muscle. If muscle regeneration occurs under hypoxic conditions either due to the injury caused by hypoxia itself or due to other causes, proliferating myoblasts respond by hypoxia-specialized adaptive mechanisms. At the same time, these myoblasts are under the influence of GCs, which under such circumstances organize the systemic response to stress. Because each of these responses might influence the regeneration process in its own way, it is important to know whether they interfere with each other or if they are in some way coordinated.

The response to hypoxia is organized mainly by the hypoxiainducible factor- $1 \alpha$ (HIF-1 $\alpha)(49)$. HIF- $1 \alpha$ is a transcriptional factor directly controlling several hundred genes encoding proteins that are involved in metabolic adaptation, vascular homeostasis, and some other adaptive processes to hypoxia $(26,37)$. The HIF-1 $\alpha$ response has been demonstrated in practically all tissues, including adult skeletal muscle (3, 26, $34,56)$. Additional, more tissue-specific factors, like HIF- $2 \alpha$ (25) and HIF-3 $\alpha$ (45), have been shown to participate in the HIF-1-organized hypoxic response. A natural antisense version of HIF-1 $\alpha$ transcript (aHIF) was also identified and proposed as a key element of a HIF- $1 \alpha$ expression negative loop regulation $(40,46)$.

The cellular response to GCs is regulated by the system composed of the tissue-specific combination of glucocorticoid receptors (GRs) and 11 $\beta$-hydroxysteroid dehydrogenases (11 $\beta$-HSDs) (1, 42). Two GR isoforms, GR $\alpha$ and GR $\beta$, organize this response; $\mathrm{GR} \alpha$ resides in the cytoplasm, acts as a ligand-dependent transcription factor, and is downregulated by increased exposure to GCs (42). GR $\beta$ does not bind GC ligands. It has been proposed that it resides in the nucleus where it controls GR $\alpha$ activity either by forming transcriptionally inactive $\mathrm{GR} \alpha / \mathrm{GR} \beta$ heterodimers preventing in this way $\mathrm{GR} \alpha$ from binding to the GC response element and/or titrating a coactivator needed by $\mathrm{GR} \alpha$ for full transcriptional activity $(14,33)$. Type 1 (11 $\beta$-HSD1) is upregulated by increased GC concentration and, although being a bidirectional enzyme, mostly generates active cortisol from inactive cortisone (42, $53)$. Type 2 (11 $\beta$-HSD2) has only dehydrogenase activity that inactivates 11 -hydroxyglucocorticoids (corticosterone, cortisol) and in this way confers specificity on less abundant aldosterone to activate mineralocorticoid receptors which bind GCs with practically the same affinity as mineralocorticoids (42).

To understand how regenerating human muscle adapts to hypoxia and how this adaptation interferes with stress response it is necessary to: 1) identify and characterize the HIF-1 $\alpha$ response in human myoblasts; 2) identify and characterize 
response to GCs in human myoblasts, and 3) investigate the effects of hypoxia on the GC stress response and the influence of this combination on the factors controlling myoblast proliferation.

The present understanding of the HIF-1 $\alpha$ response to hypoxia in human muscle is fragmentary (26) and has not been studied yet in human myoblasts. Also, the reports on the expression of GR isoforms and both types of $11 \beta$-HSD in the human muscle are not consistent. For example, Oakely et al. (33) and Pujols et al. (36) demonstrated GR $\alpha$ but failed to find GR $\beta$ in the human skeletal muscle, whereas Whorwood et al. (53) and Fruchter et al. (15) reported GC-dependent downregulation of GR $\alpha$ accompanied by upregulation of GR $\beta$ and $11 \beta$-HSD1 in human myoblasts. Early studies using Northern blotting or conventional RT-PCR did not detect 11 $\beta$-HSD2 mRNA in skeletal muscle $(1,2,52)$; however, Jang et al. (22) demonstrated 11ß-HSD2 in the in vivo human muscle and found its mRNA decreased after dexamethasone (Dex) treatment. Induced GR $\alpha$ expression has been demonstrated in hypoxic human proximal tubular cells (23), but the response to GCs is tissue specific, and therefore the response in these cells might not be the same as in human myoblasts.

Here we approached the issues raised above by: 1) following the time course of expression of HIF- $1 \alpha$ and aHIF and of HIF-1 $\alpha$ downstream targets phosphoglycerate kinase 1 (PGK1) and vascular endothelial growth factor (VEGF) in human myoblasts; their expression was determined under normal and hypoxic conditions and in combination of these with the Dex treatment; the hypoxic response was additionally characterized by studying PGK1 expression after small-interfering RNA (siRNA) silencing of HIF-1 $\alpha$; and 2) determination of the expression levels of GR $\alpha$, GR $\beta, 11 \beta-H S D 1$, and 11 $\beta-H S D 2$ under normal and hypoxic conditions and in combination of these with Dex treatment. We also tested the combined effects of Dex and hypoxia on the IL-6 secretion because IL-6 release from human myoblasts importantly facilitates muscle regeneration by promoting myoblast proliferation $(5,6,7,10)$. In our previous study, we found robust IL-6 secretion from human myoblasts that was strongly inhibited by Dex treatment (35).

\section{MATERIALS AND METHODS}

Cultured human myoblasts. All studies reported here were approved by the Ethical Commission at the Ministry of Health of the Republic of Slovenia (permit No: 63/01/99). Muscle cultures were prepared as described in detail before $(4,19,27,35)$. Briefly, myoblast cultures were prepared from muscle tissue routinely discarded at orthopedic operations. Donors were free of neuromuscular disease. Muscle tissue was cleaned of connective and adipose tissue, cut to small pieces, and trypsinized at $37^{\circ} \mathrm{C}$ to release muscle satellite cells. Isolated cells were grown in 100-mm petri dishes (BD Falcon, Franklin Lakes, NJ) in growth medium AdvancedMEM supplemented with $10 \%(\mathrm{vol} / \mathrm{vol})$ FBS, $0.3 \%$ (vol/vol) fungizone, and $0.15 \%$ (vol/ vol) gentamicin (all obtained from Invitrogen, Paisley, UK) at $37^{\circ} \mathrm{C}$ in $5 \% \mathrm{CO}_{2}$-enriched air at saturation humidity. Concentrations of fungizone (amphotericin B) and gentamicin used in our experiments correspond to 0.75 and $15 \mu \mathrm{g} / \mathrm{ml}$, respectively, which is below the concentration ranges at which fungizone $(24,47)$ and gentamicin $(11$, 17, 41) affect proliferation. Myoblast colonies were selectively trypsinized just before fusion, transferred to $75-\mathrm{cm}^{2}$ cell culture flasks, and were grown under the same conditions as the primary cultures for two to three more passages, when they were used for experiments.
Experiments were carried out in polystyrene-treated six-well plates (BD Falcon).

Treatment with Dex and introduction of hypoxia and chemical hypoxia. Myoblasts were incubated with $1 \mu \mathrm{M}$ dexamethasone phosphate (Dexamethason; Krka, Novo Mesto, Slovenia) and/or exposed either to hypoxia $\left(1 \% \mathrm{O}_{2}\right)$ or to $250 \mu \mathrm{M} \mathrm{CoCl}_{2} . \mathrm{O}_{2}(1 \%)$ is commonly used as a hypoxic condition in in vitro muscle research and corresponds to $\mathrm{PO}_{2}$ of $\sim 7.6 \mathrm{mmHg}$. Although this level of oxygen is already starting to limit aerobic metabolism (38), it is still compatible with myoblast survival and myogenesis progression (54). Frequently used treatment with $\mathrm{CoCl}_{2}$ is referred to as "chemical hypoxia," because, like decreased $\mathrm{PO}_{2}$, it also leads to increased expression of HIF- $1 \alpha$ and its downstream targets $(48,43)$. Although its precise mechanism of action is not known, the prolylhydroxylases (PHD 1-3) that regulate $\mathrm{HIF}-1 \alpha$ expression posttranslationally are probably an important site of $\mathrm{CoCl}_{2}$ action $(13,28,55)$.

Hypoxic conditions were established by flushing the Modular Incubator Chamber MC-101 (Billups-Rothenberg, Del Mar, CA) with hypoxic gas mixture $\left(1 \% \mathrm{O}_{2}-5 \% \mathrm{CO}_{2}-94 \% \mathrm{~N}_{2}\right)$ at $20-25 \mathrm{l} / \mathrm{min}$ for 5 $\mathrm{min}$. To decrease diffusional barrier for gas exchange, $0.1 \mathrm{ml}$ growth medium $/ \mathrm{cm}^{2}$ was used when culturing cells in hypoxia. Atmosphere in the Modular Incubator Chamber was at saturation humidity. Chemical hypoxia was introduced by treating myoblasts with $250 \mu \mathrm{M}$ $\mathrm{CoCl}_{2}$ (Sigma, St. Louis, MO).

Western blot analysis. Myoblasts were washed two times with ice-cold PBS and lysed in $200 \mu \mathrm{l}$ lysis buffer [20 mM Tris, $1 \mathrm{mM}$ EDTA, $10 \%$ (wt/vol) sucrose, $0.1 \%$ Triton $\mathrm{X}-100$, and $1 \%$ (vol/vol) Protease Inhibitor Cocktail (all obtained from Sigma), $\mathrm{pH}=7.4]$. Samples were scraped from the culture plates, and insoluble components were removed by centrifugation $\left(12,000 \mathrm{~g}, 10 \mathrm{~min}\right.$, at $\left.4^{\circ} \mathrm{C}\right)$. Protein content was determined in supernatants by the Bradford protein assay (Thermo Scientific Pierce, Rockford, IL).

Protein samples, prepared in Laemmli buffer, were separated in $10 \%$ NuPage Novex Bis-Tris Gel (Invitrogen) by using the XCell SureLock electrophoresis system (Invitrogen) and transferred to a polyvinylidene difluoride membrane (Millipore, Billerica, MA). Membranes were blocked in blocking buffer $[0.2 \%$ (wt/vol) I-Block (Applied Biosystems, Carlsbad, CA) and 0.3\% (vol/vol) Tween 20 (Sigma) prepared in PBS]. After an overnight incubation at $4^{\circ} \mathrm{C}$ with primary antibodies, membranes were incubated with alkaline phosphatase-conjugated secondary antibodies (Sigma). Blots were developed in 2\% ( vol/vol) NBT/BCIP (Roche, Mannheim, Germany) solution prepared in developing buffer $\left(0.1 \mathrm{M}\right.$ Tris, $0.05 \mathrm{M} \mathrm{MgCl}_{2}$, and $0.1 \mathrm{M} \mathrm{NaCl}, \mathrm{pH}$ 9.5). Quantifications were performed with the Chemi Genius BioImaging System (Syngen, Cambridge, UK).

We used primary antibodies against GR $\alpha$ (rabbit polyclonal antibody PA1-516, diluted 1:200; ABR-Affinity BioReagents, Rockford, IL), GR $\beta$ (rabbit polyclonal antibody PA3-514, diluted 1:200; ABRAffinity BioReagents), HIF-1 $\alpha$ (rabbit polyclonal antibody NB100449, diluted 1:500; Novus Biologicals, Littleton, CO), and actin (rabbit polyclonal antibody SC-1616-R, diluted 1:1,000; Santa Cruz Biotechnology, Santa Cruz, CA).

Quantitative PCR. Total RNA, extracted with the RNeasy Mini Plus Kit (Qiagen, Hilden, Germany), was reverse transcribed with a High-Capacity cDNA Reverse Transcription Kit (Applied Biosystems). Quantitative PCR (qPCR) was performed on an ABI PRISM SDS 7500 (Applied Biosystems), using TaqMan chemistry in a 96-well format. We used TaqMan Universal PCR Master Mix (Applied Biosystems) and the following Gene Expression Assays (Applied Biosystems): Hs01005213_m1 (for GR $\alpha$, see below), Hs00354508_m1 (for GR $\beta$ ), Hs00194153_m1 (for 11 $\beta$-HSD1), Hs00388669_m1 (for 11 $\beta$-HSD2), Hs00936368_m1 (for HIF-1 $\alpha$ ), 4333765F (for PGK1), Hs00153153_m1 (for aHIF), and Hs00173626_m1 (for VEGF). Gene Expression Assay Hs01005213_m1 can detect both GR $\alpha$ and GR $\beta$, but we established in our preliminary experiments that the GR $\beta$ mRNA level is $>1,000$-fold lower compared with GR $\alpha$ mRNA (data not shown). In these experiments, GR $\alpha$ mRNA was detected by 
using $800 \mathrm{nM}$ forward primer (5'-GAAGGAAACTCCAGCCAGAA$\left.3^{\prime}\right), 800 \mathrm{nM}$ reverse primer (5'-CAGCTAACATCTCGGGGAAT-3'), and $200 \mathrm{nM}$ sense probe (6FAM-5'-GCTTCCAAACATTTTTGGATAAGACCAT-3'-TAMRA) of NM_000176.2 (29). For all other $\mathrm{GR} \alpha \mathrm{mRNA}$ analyses reported in this paper, Gene Expression Assay Hs01005213_m1 was used, whereas GR $\beta$ mRNA expression was simultaneously evaluated with Hs00354508_m1 (which detects only GR $\beta$ mRNA). GR $\beta$ mRNA level was consistently at least 1,000-fold lower compared with GR $\alpha$ and GR $\beta$ mRNA combined, but in most cases the difference was 8,000- to 10,000-fold or more. Reaction efficiency of all the assays was tested by constructing relative standard curves. The slopes of the relative standard curves between target genes and endogenous controls differed by $<0.3$, and relative $\left(\Delta \Delta \mathrm{C}_{\mathrm{t}}\right)$ quantification was performed to assess expression levels of target genes. Relative quantification was also used for GR $\beta$ mRNA, although it was not possible to construct a reliable relative standard curve, since its expression level was very low (usually $\mathrm{C}_{\mathrm{t}} \geq 35$ ).

Selection of endogenous controls for qPCR. Both hypoxia and GCs affect a great number of genes, which implies careful selection of standards in qPCR determinations. To avoid artifacts resulting from endogenous control selection, we carried out two sets of experiments where either $\beta$-actin (ACTB) (4333762F) or 18S rRNA (4333760F), whose level was relatively stable under different experimental conditions in preliminary experiments (data not shown), were used. Moreover, ACTB was shown to undergo only minor changes in skeletal muscle cells during the first $24 \mathrm{~h}$ of hypoxia (50). To confirm that the fall of HIF-1 $\alpha$ mRNA after $24 \mathrm{~h}$ of hypoxia was not an artifact, we verified the result in separate experiments using cyclophilin $(4333763 \mathrm{~F})$ as an additional endogenous control (data not shown).

HIF- $1 \alpha$ knockdown by siRNA. HIF1A ON-TARGETplus SMARTpool set of four siRNAs (J-004018-07, J-004018-08, J-004018-09, and J-004018-10) (Thermo Scientific Dharmacon RNAi Technologies, Rockford, IL) were used for HIF-1 $\alpha$ knockdown experiment. Myoblasts were grown until reaching 50\% confluence. A day before transfection, growth medium was replaced by growth medium without fungizone and gentamicin. Myoblasts were transfected by Lipofectamine 2000 (Invitrogen). Transfection solution [total siRNA concentration $100 \mathrm{nM}, 2 \%$ ( $\mathrm{vol} / \mathrm{vol}$ ) lipofectamine; Invitrogen] was prepared in serum-free Opti-MEM (Invitrogen). After $24 \mathrm{~h}$, incubation transfection solution was removed and replaced by growth medium. Experiments were performed $48 \mathrm{~h}$ after the start of transfection.

Determination of IL-6 secretion from cultured human myoblasts. IL-6 secretion from human myoblasts was determined as described previously (35). In brief, an Endogen Human IL-6 ELISA Kit (Thermo Scientific Pierce Endogen) was used. IL-6 concentration was measured in cell culture supernatants and normalized to total cellular protein content (Bradford assay).

Statistics. One-way ANOVA, followed by Bonferroni post hoc test or Dunnett's test (as appropriate), was performed to test for differences among groups. Results are expressed as means \pm SE. If the normal distribution could not be assumed, data were subjected to nonparametric tests (Kruskal-Wallis test, followed by Dunn's test, or Mann-Whitney $U$-test). For experiments where two sets of data with two different endogenous controls (ACTB and 18S rRNA) are shown, one-way ANOVA (followed by Bonferroni post hoc test) was used to test for differences within each set of experiments. Statistical analyses were carried out with SPSS 15.0 for Windows and GraphPad Prism 5.

\section{RESULTS}

Expression of HIF-1 $\alpha, a H I F$, and HIF-1 $\alpha$ downstream targets in human myoblasts under hypoxic conditions without or in combination with Dex treatment. To characterize the hypoxic response in human myoblasts, we followed the time course of HIF-1 $\alpha$ expression during $24 \mathrm{~h}$ exposure to either hypoxic conditions $\left(1 \% \mathrm{O}_{2}\right)$ or $250 \mu \mathrm{M} \mathrm{CoCl}_{2}$, also referred to as chemical hypoxia, since it also results in an increased HIF-1 $\alpha$ level (see MATERIALS AND METHODS). Under both conditions, we found a peak expression level of HIF-1 $\alpha$ after 4-6 $\mathrm{h}$ of exposure; after $24 \mathrm{~h}$, it practically returned to the control level (Fig. 1A). To test if expressed HIF- $1 \alpha$ exerts its effects on the downstream targets, we determined the PGK1 mRNA level in myoblasts $24 \mathrm{~h}$ after the onset of hypoxia. This time point was selected because $24 \mathrm{~h}$ is the time when, as a result of HIF- $1 \alpha$ actions, the level of PGK1 mRNA becomes significantly increased and is also in the time frame of the effects of Dex. We found an approximately sevenfold increase of the PGK1 mRNA level after $24 \mathrm{~h}$ of hypoxia accompanied by a decreased level of HIF- $1 \alpha$ mRNA to $\sim 40 \%$ of control (Fig. $1 B)$. The decreased HIF- $1 \alpha$ mRNA level reflects the increase in the level of aHIF (Fig. 1B), which downregulates HIF-1 $\alpha$ expression (40). To show that PGK1 induction is dependent on HIF- $1 \alpha$ expression, we partially silenced HIF- $1 \alpha$ expression in myoblasts by siRNA and followed the PGK1 mRNA levels after exposure to hypoxia. The decrease of HIF- $1 \alpha$ mRNA to $\sim 40 \%$ control due to siRNA silencing led to a proportionally stronger decrease of its mRNA under hypoxic conditions (Fig. 2A). HIF- $1 \alpha$ mRNA silencing did not affect the PGK1 mRNA level in the normoxic but decreased it in the hypoxic myoblasts (Fig. $2 B)$. The decrease of HIF- $1 \alpha$ mRNA due to siRNA silencing (Fig. $2 A$ ) resulted in a proportionally lower increase of PGK1 mRNA under hypoxic conditions (Fig. 2B).

To find out if the presence of GCs change or modify the response to hypoxia described above, we determined the expression of HIF-1 $\alpha$ under normoxic and hypoxic conditions in combination with the Dex treatment. Treatment of myoblasts with $1 \mu \mathrm{M}$ Dex for $24 \mathrm{~h}$, which is the time when its effects are
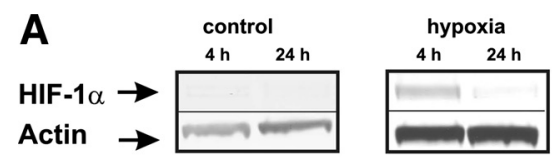

$4 \mathrm{~h}$

$6 \mathrm{~h}$

$12 \mathrm{~h}$

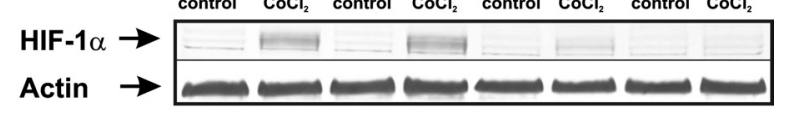

B

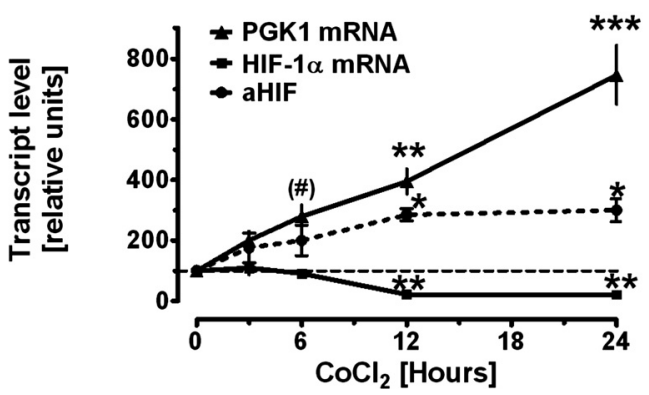

Fig. 1. Time course of hypoxia-inducible factor- $1 \alpha$ (HIF-1 $\alpha)$, the antisense version of hypoxia-inducible factor (aHIF), and phosphoglycerate kinase 1 (PGK1) mRNA changes in human myoblasts exposed to hypoxia for $24 \mathrm{~h}$. $A$ : HIF-1 $\alpha$ protein level (Western blot) in myoblasts exposed either to hypoxia $\left(1 \% \mathrm{O}_{2} ;\right.$ top $)$ or $250 \mu \mathrm{M} \mathrm{CoCl}_{2}$ (chemical hypoxia; bottom) for the indicated periods of time. Actin was used as a loading control. $B$ : transcript levels [quantitative PCR (qPCR)] of HIF-1 $\alpha$, PGK1, and aHIF in myoblasts treated with $250 \mu \mathrm{M} \mathrm{CoCl}_{2}$ for $3,6,12$, or $24 \mathrm{~h}$. Data were normalized to respective nontreated controls. ACTB was used as the endogenous control. Results are means $\pm \mathrm{SE}\left(n=3\right.$ experiments). $\# P=0.052,{ }^{*} P<0.01, * * P<0.005$, and $* * * P<0.001$ vs. respective nontreated control (Dunnett's post hoc test). 

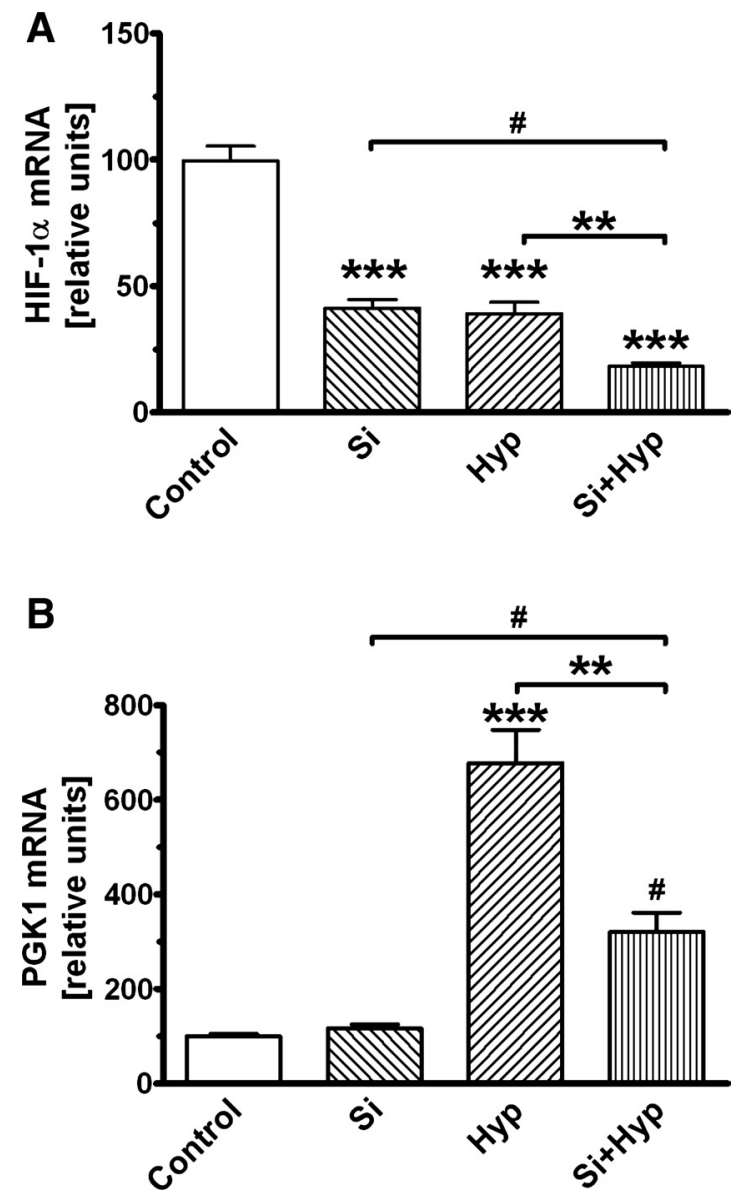

Fig. 2. The effect of HIF-1 $\alpha$ knock down on the downstream hypoxic response in human myoblasts. Level of HIF-1 $\alpha$ mRNA $(A)$ and PGK1 mRNA $(B)$ was determined (qPCR) in normal myoblasts (control) and myoblasts with siRNAsilenced HIF-1 $\alpha(\mathrm{Si})$. Both were then exposed for $24 \mathrm{~h}$ to hypoxia $\left(1 \% \mathrm{O}_{2}=\right.$ Hyp; silencing $\left.+1 \% \mathrm{O}_{2}=\mathrm{Si}+\mathrm{Hyp}\right)$. ACTB was used as the endogenous control. Data were normalized to respective normoxic controls. Results are means $\pm \operatorname{SE}(n=3)$. $\# P<0.05, * * P<0.005$, and $* * * P<0.001$ vs. control or as indicated (Bonferroni post hoc test).

expected to be already fully expressed, had no significant effect on the HIF-1 $\alpha$ protein level in either normoxic or hypoxic conditions (Fig. 3). The same lack of Dex effect was observed at the HIF- $1 \alpha$ mRNA level (Fig. $4 A$ ). The downstream effect of HIF- $1 \alpha$ on the metabolic target PGK1 mRNA expression (Fig. $4 B$ ) also remained unchanged in the Dex-treated myoblasts. In the case of angiogenic target VEGF (Fig. 4C), we observed the opposite effects of Dex treatment and hypoxia; while Dex significantly decreased, hypoxia significantly increased the level of VEGF mRNA.

The effects of Dex treatment on the expression of $G R \alpha, G R \beta$, $11 \beta-H S D 1$, and 11 -HSD2 under normoxic and hypoxic conditions. GR $\alpha$ mRNA was detected in our cultured human myoblasts and was downregulated to $\sim 60-70 \%$ of control after $24 \mathrm{~h}$ of Dex treatment under normoxic conditions. Hypoxic conditions did not significantly change this effect of Dex (Fig. 5A). At the protein level, we found a significant $\sim 40 \%$ increase of the GR $\alpha$ under the hypoxic conditions (Fig. $5 B$ ); treatment with Dex abolished this upregulation of GR $\alpha$ and reduced it to the same level as observed under normoxic conditions, i.e., to $\sim 30-40 \%$ of control (Fig. $5 B$ ).
GR $\beta$ could be detected only at the mRNA level in our experiments. However, $C_{t}$ values were in the 35 th-40th cycle range, where the reliability of the determination of the specific target mRNA becomes questionable. GR $\beta$ mRNA remained unaffected after all treatments: Dex, hypoxia, or combined (Dex + hypoxia) (Fig. 5C). Although using GR $\beta$ specific antibodies in our Western experiments, we were not able to detect a band that could reliably be ascribed to GR $\beta$. Western blot is therefore not shown.

Using real-time PCR, we found expression of both $11 \beta$ HSD1 and $11 \beta-H S D 2$ in human myoblasts. Treatment with 1 $\mu \mathrm{M}$ Dex for $24 \mathrm{~h}$ under normoxic conditions resulted in the three- to sixfold increase in 11 $\beta$-HSD1 mRNA (Fig. 6A). We also detected a $50-60 \%$ decrease of $11 \beta$-HSD2 mRNA after Dex treatment. The difference was significant if ACTB was used as a standard (Fig. 6B). These effects of Dex remained practically unchanged under hypoxic conditions, indicating their resistance to the HIF- $1 \alpha$-induced cellular adaptations to hypoxia (Fig. 6, $A$ and $B$ ).

The effects of Dex on the IL-6 secretion under hypoxic conditions. IL-6 is known as a promoter of human myoblast proliferation and therefore of human muscle regeneration $(5,6$, $7,12)$. Because Dex downregulates IL-6 secretion from human myoblasts (35), it is important to know whether and how hypoxia influences Dex-mediated downregulation of IL-6 secretion. We were unable to find any statistically significant effect of hypoxia pretreatment on the IL-6 secretion (Fig. 7A). However, using this data to determine the percent inhibition of IL-6 secretion by Dex, we found slight but statistically significant potentiation of inhibition in the hypoxia-pretreated myoblasts (Fig. 7B).

\section{DISCUSSION}

Our results show functional separation between the pathway of HIF- $1 \alpha$-organized adaptation to hypoxia and the mechanisms responsible for the regulation of the $\mathrm{GC}$ response. We demonstrated an $\mathrm{HIF}-1 \alpha$-mediated response in human myoblasts exposed to hypoxia. Since HIF-1 $\alpha$ protein and mRNA

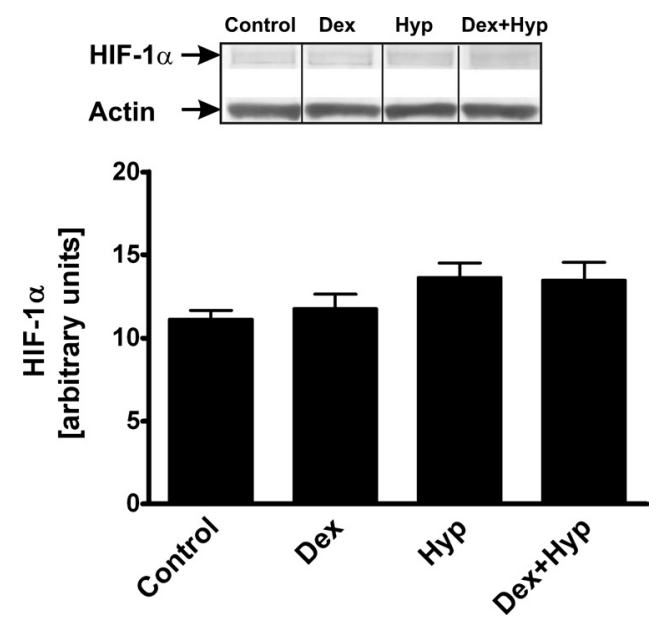

Fig. 3. HIF-1 $\alpha$ protein level in human myoblasts in the presence of Dex. HIF- $1 \alpha$ level was determined by Western blot (normalized to actin). Dex treatment, either alone (Dex) or under hypoxic conditions (Dex + Hyp), had no effect on the HIF-1 $\alpha$ level; a still slightly increased level after $24 \mathrm{~h}$ of hypoxia is statistically insignificant and remains at the same level in the Dex-treated myoblasts $(n=6)$. A representative Western blot is shown at top. 

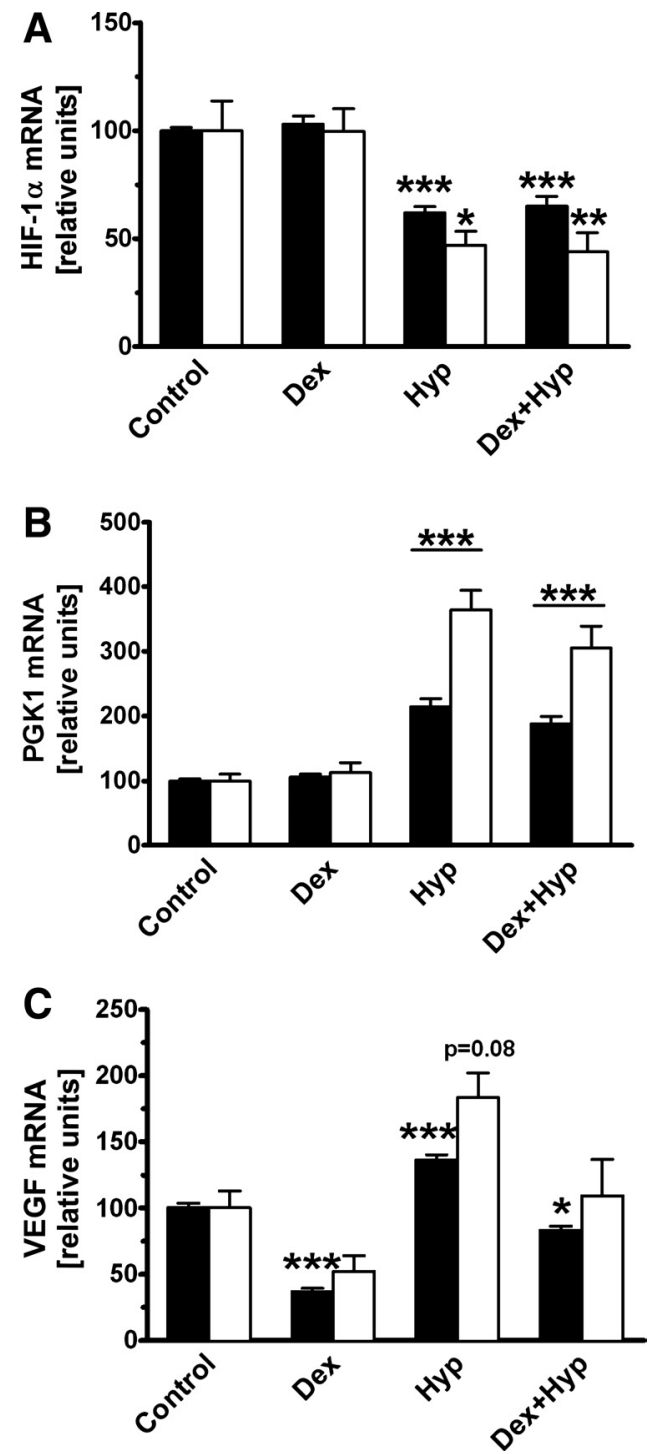

Fig. 4. Hypoxic response in human myoblasts in the presence of Dex; mRNA level (qPCR). Myoblasts were exposed for $24 \mathrm{~h}$ to $1 \mu \mathrm{M}$ Dex alone (Dex), hypoxia $\left(1 \% \mathrm{O}_{2}\right)$ alone (Hyp), or hypoxia in combination with Dex treatment (Dex + Hyp). Bars represent means \pm SE. A: HIF- $1 \alpha$ mRNA. B: PGK1 mRNA level. $C$ : vascular endothelial growth factor (VEGF) mRNA level. ACTB (filled bars) $(n=10)$ or $18 \mathrm{~S}$ rRNA (open bars) $(n=3-7)$ was used as the endogenous control. Data were normalized to respective normoxic controls. Levels of HIF-1 $\alpha$ and PGK1 mRNA in Dex vs. Hyp and Dex vs. Dex + Hyp treated groups were also statistically significant (not indicated for reasons of clarity), but there was no difference among Hyp vs. Dex + Hyp-treated groups. Although VEGF in the 18S rRNA data set showed the same biological response as those in the ACTB set, changes were not statistically significant with Bonferroni's post hoc test because of higher variability [Student's $t$-test, however, showed a significant difference $(P=0.021)$ between the control and Hyp group]. VEGF levels in Dex vs. Hyp groups were significantly different in both the ACTB and 18 S rRNA data set. $* P<0.01, * * P<0.005$, and $* * * P<0.001$ vs. respective (ACTB or 18S rRNA) control (Bonferroni post hoc test was performed separately within each data set).

levels do not reflect HIF- $1 \alpha$ activity because it is the HIF- $1 \alpha /$ HIF-1 $\beta$ dimer that acts as a transcription factor, we decided to use the expression of the HIF- $1 \alpha$ downstream target PGK1 as an indicator of HIF- $1 \alpha$ effects. The time between the increase of HIF- $1 \alpha$ and its effects determined at the level of expression of PGK1 is in accordance with the observations in other cells and tissues $(16,21)$, suggesting that the mechanism is conservative among tissues. This response, which has not been reported in human myoblasts before, remained practically unchanged if hypoxic myoblasts were simultaneously treated with Dex. We observed mutual independence also when we studied the opposite, i.e., the influence of hypoxia on the
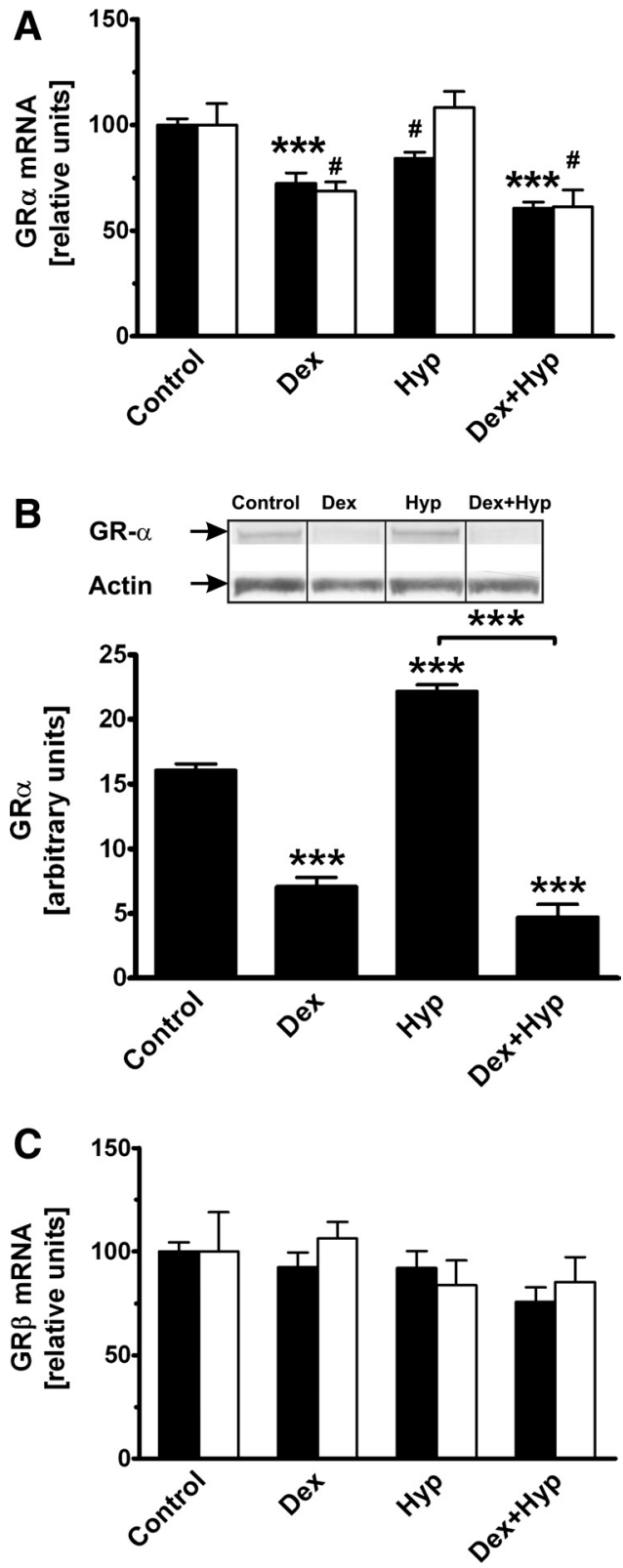

Fig. 5. The effects of Dex on the glucocorticoid receptor (GR) $\alpha$ and GR $\beta$ expression in human myoblasts under normoxic or hypoxic conditions. Human myoblasts were treated for $24 \mathrm{~h}$ with $1 \mu \mathrm{M}$ Dex, Hyp $\left(1 \% \mathrm{O}_{2}\right)$, or both (Dex + Hyp). Bars represent means \pm SE. A: GR $\alpha$ mRNA (qPCR). $B$ : GR $\alpha$ protein level (Western blot). $C$ : GR $\beta$ mRNA (qPCR). ACTB (filled bars; $n=10$ ) or 18S rRNA (open bars: $n=5-9$ ) was used as the endogenous control. Data were normalized to respective normoxic controls. None of the treatments had any significant effect on the GR $\beta$ mRNA level. GR $\alpha$ protein level was normalized to actin ( $n=4-5)$. There is no difference among groups (Dex vs. Dex + Hyp). A representative Western blot is shown at top in $B$. $\# P<0.05$ and $* * * P<0.001$ vs. (ACTB or $18 \mathrm{~S}$ rRNA) control or as indicated (Bonferroni post hoc test was performed separately within each data set with different endogenous controls). 

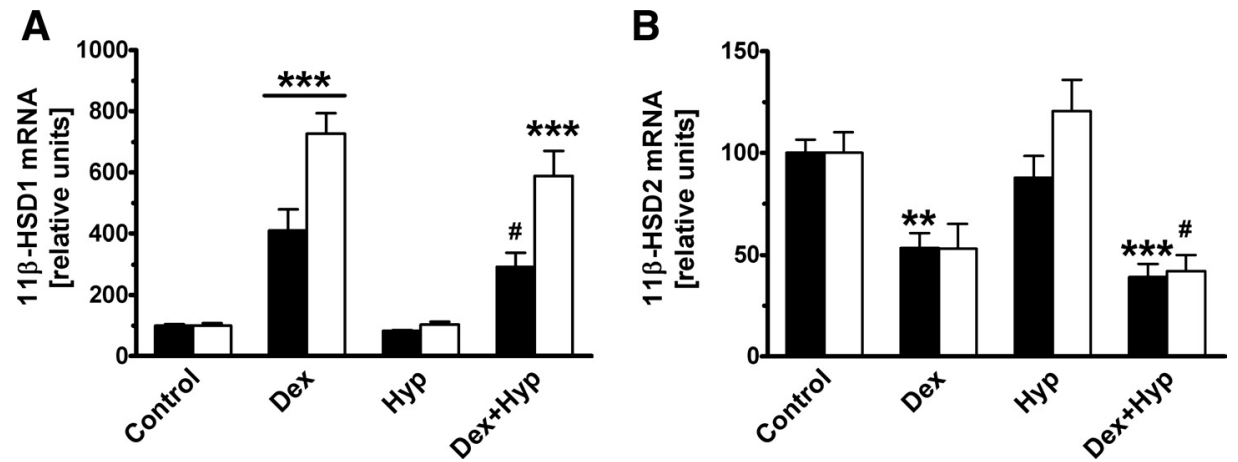

Fig. 6. The effects of Dex on the expression of $11 \beta$-hydroxysteroid dehydrogenases (11ß-HSD) 1 mRNA $(A)$ and $11 \beta$-HSD2 mRNA (B) under normoxic or hypoxic conditions (qPCR). Human myoblasts were treated for $24 \mathrm{~h}$ with $1 \mu \mathrm{M}$ Dex, Hyp $\left(1 \% \mathrm{O}_{2}\right)$, or both (Dex + Hyp). Bars represent means \pm SE. ACTB (filled bars) $(n=6)$ or $18 \mathrm{~S}$ rRNA (open bars) $(n=3)$ was used as the endogenous control. Data are normalized to respective normoxic controls. Hyp group was also significantly different from Dex and Dex + Hyp (not indicated for reasons of clarity). There is no difference among groups (Dex vs. Dex + Hyp) in either $A$ or $B$. $\# P<0.05$, **P $<0.005$, and $* * * P<0.001$ vs. respective (ACTB or $18 \mathrm{~S}$ rRNA) control (Bonferroni post hoc test was performed separately within each data set with different endogenous controls).

system responsible for the reception of GC signals. We demonstrated expression of GR $\alpha, 11 \beta-H S D 1$, and $11 \beta-H S D 2$ in

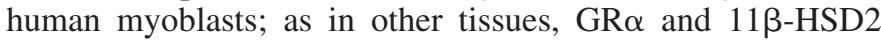
were downregulated and $11 \beta$-HSD1 was upregulated by Dex. However, this response was not significantly different if Dex treatment proceeded under the hypoxic conditions.

Because both mechanisms, one mediated by HIF- $1 \alpha$ and another by GRs and $11 \beta$-HSDs, can be considered as a response to stress imposed by the lack of oxygen, one would expect coordination among them. Their separation is therefore on the first sight surprising, but could be explained on the evolutionary basis. HIF- $1 \alpha$-mediated adaptation to hypoxia can be understood as a stress response organized at the level of an individual cell. It is phylogenetically older than the GR response; its vertebrate variant diverged from an even older ancestor about 500 millions years ago $(20,51)$ and remained preserved with further development of higher organisms. On the other hand, the stress response mediated by GC hormones released from the adrenal cortex is designed as a stress adaptation at the level of the whole organism. It was developed later [adrenal steroid receptors have not been found earlier than in vertebrates (8)] and does not work in a way to be protective at the level of the individual cells or individual tissues. For example, GCs promote protein catabolism in the skeletal muscle to provide substrates for gluconeogenesis in liver, which is a defensive measure toward hypoglycemia that must be prevented under stressful circumstances. Different levels of stress defense therefore also necessitate two separated sets of defense mechanisms.

A clear separation between the GC-mediated stress response and HIF- $1 \alpha$-mediated adaptation to hypoxia was observed at the regulation of the VEGF mRNA, which was downregulated by Dex and upregulated by hypoxia. The difference between the Dex effects on VEGF mRNA and another direct HIF-1 $\alpha$ downstream target (PGK1 mRNA, which was not affected by Dex) can be explained by different roles of the two proteins. PGK1 is a glycolytic enzyme and therefore has very specific intracellular function, whereas VEGF is a growth factor released from the myoblasts. Physiological meaning of HIF-1 $\alpha$ induced VEGF upregulation is to promote vascularization as a compensation of hypoxia. However, VEGF also has a wide spectrum of other effects at the systemic level that must be regulated when the stress response is organized in the organism, which explains its downregulation by Dex (18). Separation of the two responses, however, cannot be generalized, since it seems to be tissue-specific. For example, Leonard et al. (23) reported potentiation of GC activity in hypoxia in the HK-2 human proximal tubular epithelial cells of the kidney.

Additional explanation for the independence of the GC response to hypoxia might be that GC actions in human myoblasts are not limited to the stress response. GCs are known to participate at the development of the mammalian organisms at their early stages (42), which might also be their role in the human myoblasts. mRNA expression of all compo-
Fig. 7. The effect of hypoxia pretreatment (preHyp) on the effects of Dex on the IL-6 secretion from human myoblasts $(A)$ and on Dex inhibition of IL-6 secretion (B). Myoblasts were either treated for $24 \mathrm{~h}$ with $1 \mu \mathrm{M}$ Dex under normoxic conditions or first exposed for 24 $\mathrm{h}$ to hypoxia $\left(1 \% \mathrm{O}_{2}\right)$ and then treated for $24 \mathrm{~h}$ with 1 $\mu \mathrm{M}$ Dex (preHyp + Dex). A: lines represent means of each respective group of measurements, $n=18$. $* * * P<$ 0.001 as indicated (Dunn's test). $\# P<0.05$ vs. Dex (Mann-Whitney $U$-test).
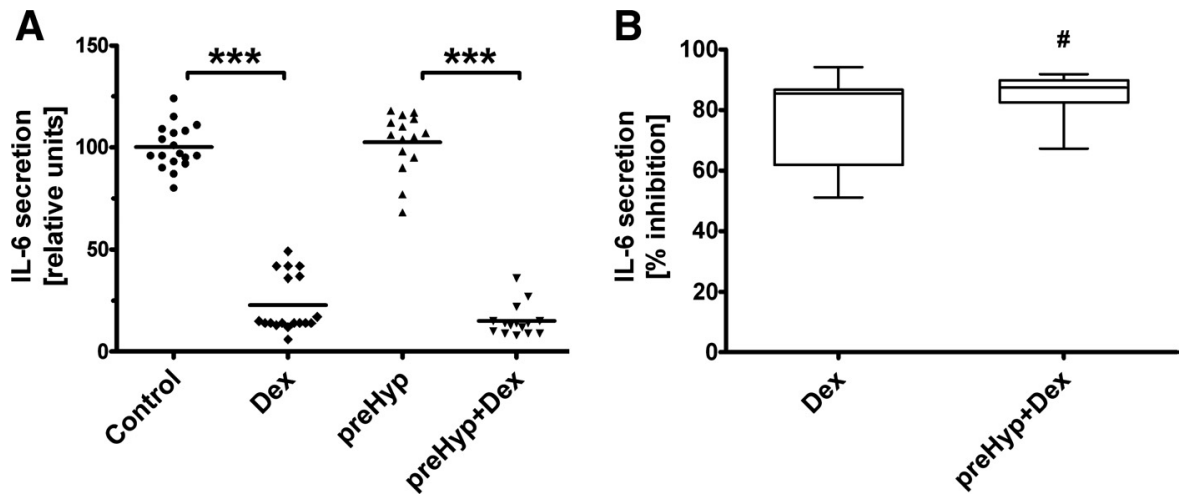
nents constituting GC response suggests that myoblasts are well equipped for the adaptation and fine tuning of the GC response in various situations. This observation supports an alternative physiological role of this response. Especially intriguing is the role of $11 \beta-\mathrm{HSD} 2$, the actions of which are essential for the proper mineralocorticoid activity (see Introduction). These actions have a clear physiological meaning in the kidney, although its role in human myoblasts remains to be established.

One exception from the mutual independence of the two mechanisms described above was upregulation of GR $\alpha$ for $\sim 40 \%$ under hypoxic conditions. One can speculate that, similar to the well-documented increased stability of HIF- $1 \alpha$ $(13,26,44)$, the stability of this GR was also increased under hypoxic conditions. This effect was, however, annihilated by Dex, suggesting that hypoxia-protected GR $\alpha$ is overridden by the well-known acceleration of protein ubiquitination and subsequent catabolism induced by GCs in the muscle tissue.

A consistent finding in our experiments was a decreased level of HIF- $1 \alpha$ mRNA to $\sim 40-50 \%$ of control after $24 \mathrm{~h}$ of hypoxia. This observation can be explained by the concomitant and complementary increase in aHIF. The role of this natural antisense version of HIF- $1 \alpha$ transcript, reported in the human myoblasts for the first time in this paper, is to act as a negative loop regulation of HIF- $1 \alpha$ expression serving in this way as a stabilizer of expression of mRNAs induced by hypoxia $(32,39$, $40,46,30,31)$. Such decrease of HIF-1 $\alpha$ mRNA was also observed in the mouse liver after prolonged exposure of mice to hypoxia (52) and in THP-1 cells already after $6 \mathrm{~h}$ of hypoxia (14). Besides, our finding that the level of PGK1 mRNA, which is a downstream target of HIF-1 $\alpha$, changes in proportion to the level of HIF-1 $\alpha$ mRNA also suggests that HIF- $1 \alpha-$ regulated adaptation to hypoxia takes place also at the mRNA level and not only at the level of protein stability $(26,44)$. Although short-term regulation is exerted at the protein level, as also demonstrated in our experiments, there is also a mid- or long-term feedback regulation at the transcriptional level maintaining the HIF- $1 \alpha$ response within the protective limits.

Our observations on the expression of GR $\beta$ in human myoblasts are in accordance with the reports of Oakley et al. (33) and Pujols et al. (36) who failed to find GR $\beta$ protein in the human skeletal muscle. We were able to detect mRNA of GR $\beta$ by real-time PCR, but only at the very low level close to the detection limit. Our results therefore do not support the participation of GR $\beta$ in organizing the GC response in human myoblasts.

It is well documented that IL-6 stimulates myoblast proliferation $(5,6,7,10)$. Because proliferation of myoblasts is the only part of the muscle regeneration where new nuclei and therefore the origins of the formation of new muscle mass are formed $(9,12)$, this stage decisively determines the mass of the regenerated muscle tissue. In our previous study, we demonstrated that Dex inhibits IL-6 secretion from human myoblasts (35). Here we show that this effect of Dex remains practically unchanged under hypoxic conditions except for a mild hypersensitivity of the IL-6 secretion inhibition by Dex. Together with our observation on VEGF, which is downregulated by Dex and upregulated in hypoxia, this observation additionally supports our conclusion that the HIF- $\alpha$ response to hypoxia is functionally separated from the system controlling GC actions in the in vitro regenerating human skeletal muscle.

\section{Perspectives and Significance}

Together with our previous studies on cultured human muscle $(19,27,35)$, this report clearly demonstrates that, although morphologically poorly developed, human myoblasts are equipped with the complex molecular apparatus that enables them to respond specifically to various environmental stimuli. Here we demonstrated for the first time absence of synergism between the pathway of HIF-1 $\alpha$-organized adaptation to hypoxia and the mechanisms responsible for the regulation of the GC stress response. Although on the first sight surprising, this mutual independence can be explained on the evolutionary basis. However, our observations were obtained under in vitro conditions, and complementary in vivo studies are needed to confirm this conclusion. Detailed understanding of the mechanisms underlying these responses are essential for the design of the therapy that would improve muscle regeneration and in this way alleviate various and numerous conditions affecting skeletal muscle.

\section{ACKNOWLEDGMENTS}

We gratefully acknowledge help from Branka Wraber. Bojana Ziberna and Zvonka Frelih are acknowledged for technical assistance.

\section{GRANTS}

This study was supported by the Slovenian Research Agency. D. Filipovic was a recipient of a short-term scholarship from Federation of European Biochemical Societies and a stipend from Ad Futura Agency of Slovenia.

\section{DISCLOSURES}

No conflicts of interest are declared by the authors.

\section{REFERENCES}

1. Abdallah BM, Beck-Nielsen H, Gaster M. Increased expression of 11beta-hydroxysteroid dehydrogenase type 1 in type 2 diabetic myotubes. Eur J Clin Invest 35: 627-634, 2005.

2. Albiston AL, Obeyesekere VR, Smith RE, Krozowski ZS. Cloning and tissue distribution of the human 11 beta-hydroxysteroid dehydrogenase type 2 enzyme. Mol Cell Endocrinol 105: R11-R17, 1994.

3. Ameln H, Gustafsson T, Sundberg CJ, Okamoto K, Jansson E, Poellinger L, Makino Y. Physiological activation of hypoxia inducible factor-1 in human skeletal muscle. FASEB J 19: 1009-1011, 2005.

4. Askanas V, Kwan H, Alvarez RB, Engel WK, Kobayashi T, Martinuzzi A, Hawkins EF. De novo neuromuscular junction formation on human muscle fibers cultured in monolayer and innervated by foetal rat spinal cord: ultrastructural and ultrastructural-cytochemical studies. $J$ Neurocyto 16: 523-537, 1987.

5. Austin L, Burgess AW. Stimulation of myoblast proliferation in culture by leukaemia inhibitory factor and other cytokines. J Neurol Sci 101: 193-197, 1991.

6. Austin L, Bower J, Kurek J, Vakakis N. Effects of leukaemia inhibitory factor and other cytokines on murine and human myoblast proliferation. $J$ Neurol Sci 112: 185-191, 1992.

7. Baeza-Raja B, Munoz-Canoves P. p38 MAPK-induced nuclear factorkappaB activity is required for skeletal muscle differentiation: role of interleukin-6. Mol Biol Cell 15: 2013-2026, 2004.

8. Baker ME. Co-evolution of steroidogenic and steroid-inactivating enzymes and adrenal and sex steroid receptors. Mol Cell Endocrinol 215: 55-62, 2004.

9. Bischoff R. The satellite cell and muscle regeneration. In: Myology, edited by Engel AG and Franzini-Armstrong C. New York, NY: McGraw Hill, 1994. p. 97-118.

10. Cantini M, Massimino ML, Rapizzi E, Rossini K, Catani C, Dalla Libera L, Carraro U. Human satellite cell proliferation in vitro is regulated by autocrine secretion of IL- 6 stimulated by a soluble factor(s) released by activated monocytes. Biochem Biophys Res Commun 216: $49-53,1995$. 
11. Chang Y, Goldberg VM, Caplan AI. Toxic effects of gentamicin on marrow-derived human mesenchymal stem cells. Clin Orthop Relat Res 452: 242-249, 2006.

12. Chargé SB, Rudnicki MA. Cellular and molecular regulation of muscle regeneration. Physiol Rev 84: 209-238, 2004.

13. Epstein AC, Gleadle JM, McNeill LA, Hewitson KS, O'Rourke J, Mole DR, Mukherji M, Metzen E, Wilson MI, Dhanda A, Tian YM, Masson N, Hamilton DL, Jaakkola P, Barstead R, Hodgkin J, Maxwell PH, Pugh CW, Schofield CJ, Ratcliffe PJC. Elegans EGL-9 and mammalian homologs define a family of dioxygenases that regulate HIF by prolyl hydroxylation. Cell 107: 43-54, 2001.

14. Frede S, Stockmann C, Winning S, Freitag P, Fandrey J. Hypoxiainducible factor (HIF) 1alpha accumulation and HIF target gene expression are impaired after induction of endotoxin tolerance. J Immunol 182: 6470-6476, 2009.

15. Fruchter O, Kino T, Zoumakis E, Alesci S, De Martino M, Chrousos G, Hochberg Z . The human glucocorticoid receptor (GR) isoform $\beta$ differentially suppresses GR $\alpha$-induced transactivation stimulated by synthetic glucocorticoids. J Clin Endocrinol Metab 90: 3505-3509, 2005.

16. Gao L, Mejías R, Echevarría M, López-Barneo J. Induction of the glucose-6-phosphate dehydrogenase gene expression by chronic hypoxia in PC12 cells. FEBS Lett 569: 256-260, 2004.

17. Goetz IE, Moklebust R, Warren CJ. Effects of some antibiotics on the growth of human diploid skin fibroblasts in cell culture. In Vitro 15: 114-119, 1979.

18. Greenberger S, Boscolo E, Adini I, Mulliken JB, Bischoff J. Corticosteroid suppression of VEGF-A in infantile hemangioma-derived stem cells. N Engl J Med 362: 1005-1013, 2010.

19. Grubic Z, Komel R, Walker WF, Miranda AF. Myoblast fusion and innervation with rat motor nerve alter distribution of acetylcholinesterase and its mRNA in cultures of human muscle. Neuron 14: 317-327, 1995.

20. Hampton-Smith RJ, Peet DJ. From polyps to people: a highly familiar response to hypoxia. Ann NY Acad Sci 1177: 19-29, 2009.

21. Higgins DF, Biju MP, Akai Y, Wutz A, Johnson RS, Haase VH. Hypoxic induction of CTGF is directly mediated by HIF-1. Am J Physiol Renal Physiol 287: F1223-F1232, 2004.

22. Jang C, Obeyesekere VR, Dilley RJ, Krozowski Z, Inder WJ, Alford FP. Altered activity of 11beta-hydroxysteroid dehydrogenase types 1 and 2 in skeletal muscle confers metabolic protection in subjects with type 2 diabetes. J Clin Endocrinol Metab 92: 3314-3320, 2007.

23. Leonard MO, Godson C, Brady HR, Taylor CT. Potentiation of glucocorticoid activity in hypoxia through induction of the glucocorticoid receptor. J Immunol 174: 2250-2257, 2005.

24. Lin ZY, Chuang WL, Chuang YH. Amphotericin B up-regulates angiogenic genes in hepatocellular carcinoma cell lines. Eur J Clin Invest 39: 239-245, 2009.

25. Loboda A, Jozkowicz A, Dulak J. HIF-1 and HIF-2 transcription factors-similar but not identical. Mol Cells 29: 435-442 2010.

26. Lundby C, Calbet JAL, Robach P. The response of human skeletal muscle tissue to hypoxia. Cell Mol Life Sci 66: 3615-3623, 2009.

27. Mars T, King MP, Miranda AF, Walker WF, Mis K, Grubic Z. Functional innervation of cultured human skeletal muscle proceeds by two modes with regard to agrin effects. Neuroscience 118: 87-97, 2003.

28. Maxwell PH, Salnikow K. HIF-1: an oxygen and metal responsive transcription factor. Cancer Biol Ther 3: 29-35, 2004.

29. Melo MR, Faria CD, Melo KC, Reboucas NA, Longui CA. Real-time PCR quantitation of glucocorticoid receptor alpha isoform (Abstract). BMC Mol Biol 5: 19, 2004.

30. Mounier R, Pedersen BK, Plomgaard P. Muscle-specific expression of hypoxia-inducible factor in human skeletal muscle. Exp Physiol 95: 899-907, 2010.

31. Mounier R, Pialoux V, Schmitt L, Richalet JP, Robach P, Coudert J, Clottes E, Fellmann N. Effects of acute hypoxia tests on blood markers in high-level endurance athletes. Eur J Appl Physiol 106: 713-720, 2009.

32. Neckers LM. aHIF: the missing link between HIF-1 and VHL? J Natl Cancer Inst 91: 106-107, 1999.

33. Oakley RH, Webster JC, Sar M, Parker CR Jr, Cidlowski JA. Expression and subcellular distribution of the beta-isoform of the human glucocorticoid receptor. Endocrinology 138: 5028-5038, 1997.

34. Pisani DF, Dechesne CA. Skeletal muscle HIF-1alpha expression is dependent on muscle fiber type. J Gen Physiol 126: 173-178, 2005.

35. Prelovsek O, Mars T, Jevsek M, Podbregar M, Grubic Z. High dexamethasone concentration prevents stimulatory effects of TNF- $\alpha$ and
LPS on IL-6 secretion from the precursors of human muscle regeneration. Am J Physiol Regul Integr Comp Physiol 291: R1651-R1656, 2006.

36. Pujols L, Mullol J, Roca-Ferrer J, Torrego A, Xaubet A, Cidlowski JA, Picado C. Expression of glucocorticoid receptor $\alpha$ - and $\beta$-isoforms in human cells and tissues. Am J Physiol Cell Physiol 283: C1324-C1331, 2002.

37. Rey S, Semenza GL. Hypoxia-inducible factor-1-dependent mechanisms of vascularization and vascular remodelling. Cardiovasc Res 86: 236-242, 2010.

38. Richmond KN, Shonat RD, Lynch RM, Johnson PC. Critical $\mathrm{PO}_{2}$ of skeletal muscle in vivo. Am J Physiol Heart Circ Physiol 277: H1831H1840, 1999.

39. Rossignol F, de Laplanche E, Mounier R, Bonnefont J, Cayre A, Godinot C, Simonnet H, Clottes E. Natural antisense transcripts of HIF-1alpha are conserved in rodents. Gene 339: 121-130, 2004.

40. Rossignol F, Vaché C, Clottes E. Natural antisense transcripts of hypoxia-inducible factor 1alpha are detected in different normal and tumour human tissues. Gene 299: 135-140, 2002.

41. Schafer TW, Pascale A, Shimonaski G, Came PE. Evaluation of gentamicin for use in virology and tissue culture. Appl Microbiol 23: 565-570, 1972.

42. Schimmer BP, Parker KL. Adrenocorticotropic hormone; adrenocortical steroids and their synthetic analogs; inhibitors of the synthesis and actions of adrenocortical hormones. In: Goodman \& Gilman's The Pharmacological Basis of Therapeutics, edited by Brunton LL, Lazo JS, and Parker LL. New York, NY: McGraw-Hill, 2006, p. 1587-1612.

43. Semenza GL, Roth PH, Fang HM, Wang GL. Transcriptional regulation of genes encoding glycolytic enzymes by hypoxia-inducible factor $1 . J$ Biol Chem 269: 23757-23763, 1994.

44. Stroka DM, Burkhardt T, Desbaillets I, Wenger RH, Neil DA, Bauer C, Gassmann M, Candinas D. HIF-1 is expressed in normoxic tissue and displays an organ-specific regulation under systemic hypoxia. FASEB $J$ 15: 2445-2453, 2001.

45. Tanaka T, Wiesener M, Bernhardt W, Eckardt KU, Warnecke C. The human HIF (hypoxia-inducible factor)-3alpha gene is a HIF-1 target gene and may modulate hypoxic gene induction. Biochem $J$ 424: 143-151, 2009.

46. Uchida T, Rossignol F, Matthay MA, Mounier R, Couette S, Clottes E, Clerici C. Prolonged hypoxia differentially regulates hypoxia-inducible factor (HIF)-1alpha and HIF-2alpha expression in lung epithelial cells: implication of natural antisense HIF-1alpha. J Biol Chem 279: 1487114878, 2004.

47. Walls EV, Kay JE. Inhibition of proliferation of a murine myeloma cell line and mitogen-stimulated B lymphocytes by the antibiotic amphotericin B (Fungizone). Immunology 47: 115-121, 1982.

48. Wang GL, Semenza GL. General involvement of hypoxia-inducible factor 1 in transcriptional response to hypoxia. Proc Natl Acad Sci USA 90: 4304-4308, 1993.

49. Wang GL, Semenza GL. Purification and characterization of hypoxiainducible factor 1. J Biol Chem 270: 1230-1237, 1995.

50. Webster KA. Regulation of glycolytic enzyme RNA transcriptional rates by oxygen availability in skeletal muscle cells. Mol Cell Biochem 77: 19-28, 1987

51. Webster KA. Evolution of the coordinate regulation of glycolytic enzyme genes by hypoxia. J Exp Biol 206: 2911-2922, 2003.

52. Wenger RH, Rolfs A, Spielmann P, Zimmermann DR, Gassmann M. Mouse hypoxia-inducible factor-1alpha is encoded by two different mRNA isoforms: expression from a tissue-specific and a housekeepingtype promoter. Blood 91: 3471-3480, 1998.

53. Whorwood CB, Donovan SJ, Wood PJ, Phillips DI. Regulation of glucocorticoid receptor alpha and beta isoforms and type I 11beta-hydroxysteroid dehydrogenase expression in human skeletal muscle cells: a key role in the pathogenesis of insulin resistance? J Clin Endocrinol Metab 86: 2296-2308, 2001.

54. Yun Z, Lin Q, Giaccia AJ. Adaptive myogenesis under hypoxia. Mol Cell Biol 25: 3040-3055, 2005.

55. Zhang H, Qian DZ, Tan YS, Lee K, Gao P, Ren YR, Rey S, Hammers H, Chang D, Pili R, Dang CV, Liu JO, Semenza GL. Digoxin and other cardiac glycosides inhibit HIF-1alpha synthesis and block tumor growth. Proc Natl Acad Sci USA 105: 19579-19586, 2008.

56. Zoll J, Ponsot E, Dufour S, Doutreleau S, Ventura-Clapier R, Vogt M, Hoppeler H, Ruddy Richard R, Flück M. Exercise training in normobaric hypoxia in endurance runners. III. Muscular adjustments of selected gene transcripts. J Appl Physiol 100: 1258-1266, 2006. 